\title{
Mechanisms and Alterations of Cardiac Ion Channels Leading to Disease: Role of Ankyrin-B in Cardiac Function
}

\author{
Holly C. Sucharski ${ }^{1,2,+}$, Emma K. Dudley ${ }^{1,2,+}$, Caullin B.R. Keith ${ }^{1,2}$, Mona El Refaey ${ }^{1,2}$, \\ Sara N. Koenig 1,2,*iD and Peter J. Mohler 1,2 \\ 1 Dorothy M. Davis Heart and Lung Research Institute, The Ohio State University Wexner Medical Center, \\ Columbus, OH 43210, USA; holly.sucharski@osumc.edu (H.C.S.); emma.dudley@osumc.edu (E.K.D.); \\ Caullin.Keith@osumc.edu (C.B.R.K.); Mona.elrefaey@osumc.edu (M.E.R.); peter.mohler@osumc.edu (P.J.M.) \\ 2 Departments of Physiology and Cell Biology and Internal Medicine, Division of Cardiovascular Medicine, \\ The Ohio State University College of Medicine and Wexner Medical Center, Columbus, OH 43210, USA \\ * Correspondence: sara.koenig@osumc.edu; Tel.: +1-614-366-0510 \\ + Denotes equal contribution.
}

Received: 2 January 2020; Accepted: 28 January 2020; Published: 31 January 2020

check for updates

\begin{abstract}
Ankyrin-B (encoded by ANK2), originally identified as a key cytoskeletal-associated protein in the brain, is highly expressed in the heart and plays critical roles in cardiac physiology and cell biology. In the heart, ankyrin-B plays key roles in the targeting and localization of key ion channels and transporters, structural proteins, and signaling molecules. The role of ankyrin-B in normal cardiac function is illustrated in animal models lacking ankyrin-B expression, which display significant electrical and structural phenotypes and life-threatening arrhythmias. Further, ankyrin-B dysfunction has been associated with cardiac phenotypes in humans (now referred to as "ankyrin-B syndrome") including sinus node dysfunction, heart rate variability, atrial fibrillation, conduction block, arrhythmogenic cardiomyopathy, structural remodeling, and sudden cardiac death. Here, we review the diverse roles of ankyrin-B in the vertebrate heart with a significant focus on ankyrin-B-linked cell- and molecular-pathways and disease.
\end{abstract}

Keywords: ankyrin-B; ANK2; ion channels; cardiovascular disease

\section{Introduction: Ankyrin Proteins}

The ankyrin family of polypeptides was first identified in the erythrocyte plasma membrane in 1979 by Bennett and Stenbuck [1]. Following this discovery, ankyrin was discovered in various organs and cell types, including brain [2-4] and myogenic cells [5,6]. We now know that ankyrins are derived from three ankyrin genes: ANK1, ANK2, and ANK3 [7-9]. ANK1 encodes ankyrin-R (AnkR), ANK2 encodes ankyrin-B (AnkB), and $A N K 3$ encodes ankyrin-G (AnkG) (Table 1). 
Table 1. Brief summary of ankyrin family proteins: ankyrin-R, ankyrin-B, ankyrin-G.

\begin{tabular}{|c|c|c|c|}
\hline & Ankyrin-R & Ankyrin-B & Ankyrin-G \\
\hline Tissue Expression & $\begin{array}{l}\text { erythrocytes [1], myelinated axons [10], } \\
\text { striated muscle [11] }\end{array}$ & $\begin{array}{c}\text { ubiquitously expressed, } \\
\text { cardiomyocytes (T-tubules, SR, } \\
\text { plasma membrane) [12], neurons [8] }\end{array}$ & $\begin{array}{l}\text { ubiquitously expressed, neurons (AIS, } \\
\text { and nodes of Ranvier) [13], } \\
\text { cardiomyocytes (intercalated disc) [14] }\end{array}$ \\
\hline $\begin{array}{l}\text { Examples of Binding } \\
\text { Partners }\end{array}$ & $\begin{array}{l}\text { CD44 [15], NKA [16], Rh type A } \\
\text { glycoprotein [17], obscurin [11] }\end{array}$ & $\begin{array}{c}\text { PP2A [12,13], NCX [12], NKA [18], } \\
\text { Kir6.2 [12,13], Cav 1.3 [19], } \\
\beta \text { II-spectrin [20] }\end{array}$ & $\begin{array}{l}\text { Nav1.6, } \beta \text { IV-spectrin, L1CAMs }[1,21,22], \\
\text { plakophilin-2 [23] Nav1.5 [14] }\end{array}$ \\
\hline Isoforms & sAnk1.5, 1.6, 1.7, and 1.9 [11] & $\begin{array}{l}\text { AnkB-188 and AnkB-212 [24]. Giant } \\
\text { AnkB (440-kD) }\end{array}$ & Giant AnkG (480-kD) [25] \\
\hline $\begin{array}{l}\text { Disease associated with } \\
\text { variants }\end{array}$ & hereditary spherocytosis [26] & $\begin{array}{c}\text { Ankyrin B syndrome: SCD, SND, AF, } \\
\text { LQTS, VT, bradycardia, syncope [12], } \\
\text { ARVC [27] }\end{array}$ & $\begin{array}{c}\text { Brugada syndrome [12], dilated } \\
\text { cardiomyopathy [28], cognitive } \\
\text { disabilities [29] }\end{array}$ \\
\hline \multicolumn{4}{|c|}{$\begin{array}{l}\mathrm{SR}=\text { sarcoplasmic reticulum, } \mathrm{AIS}=\text { axon initial segments, } \mathrm{NKA}=\mathrm{Na}^{+} / \mathrm{K}^{+} \text {ATPase, } \mathrm{PP} 2 \mathrm{~A}=\text { protein phosphatase } 2 \mathrm{~A}, \\
\mathrm{NCX}=\mathrm{Na}^{+} / \mathrm{Ca}^{2+} \text { exchanger, Kir6. } 2=\text { inward rectifier potassium channel, } \mathrm{Ca} \mathrm{V} 1.3=\text { voltage-gated calcium channel, } \\
\mathrm{L} 1 \mathrm{CAMs}=\mathrm{L} 1 \text { family of neural cell adhesion molecules, } \mathrm{SCD}=\text { sudden cardiac death, SND = sinus node disease, } \\
\mathrm{AF}=\text { atrial fibrillation, LQTS = long QT syndrome, } \mathrm{VT}=\text { ventricular tachycardia, ARVC = arrhythmogenic right } \\
\text { ventricular cardiomyopathy. }\end{array}$} \\
\hline
\end{tabular}

Ankyrin- $\mathrm{R}$ is primarily expressed in erythrocytes and was the first ankyrin identified as an adaptor protein [1], linking erythrocyte membrane proteins to the actin-based cytoskeleton [30]. AnkR is important for the structural integrity and organization of the erythrocyte membrane. Moreover, loss-of-function variants in human $A N K 1$ have been linked to $\sim 50 \%$ of hereditary spherocytosis cases [31], a complex form of hemolytic anemia that affects 1:2000 people of Northern European descent [26] and results from a loss of membrane surface tension in red blood cells [32]. AnkR regulates erythrocyte membrane expression of CD44 [15], $\mathrm{Na}^{+} / \mathrm{K}^{+}$ATPase (NKA) [16], and the Rh type A glycoprotein [17]. Although AnkR is primarily expressed in erythrocytes, AnkR is also expressed in myelinated axons [10]. ANK1 also encodes four small ankyrin-1 isoforms (sAnk1.5, 1.6, 1.7, and 1.9) that are highly expressed in striated muscle. These isoforms bind obscurin and stabilize the sarcoplasmic reticulum in striated muscle [11].

Ankyrin-B was first identified in the brain [8] and has since been identified as a critical adaptor and scaffolding protein in the heart, that mediates the interaction of integral membrane proteins with the spectrin-actin cytoskeletal network $[13,33]$. ANK2 encodes multiple isoforms that may contribute to disease. AnkB will be reviewed in detail below.

Ankyrin-G plays an important role across multiple excitable tissues. In the brain, AnkG links integral membrane proteins with the actin/spectrin-based membrane skeleton at axon initial segments (AIS) including $\mathrm{Na}_{\mathrm{V}} 1.6, \beta I V$ spectrin, and L1CAMs [21,22,33]. In the heart, AnkG is required for localization of $\mathrm{Na}_{\mathrm{V}} 1.5$ and CaMKII to the cardiomyocyte intercalated disc [13,14,34]. In mice selectively lacking AnkG expression in cardiomyocytes, $\beta I V$-spectrin and $\mathrm{Na}_{\mathrm{V}} 1.5$ expression and localization are disrupted, and voltage-gated $\mathrm{Na}_{\mathrm{V}}$ channel activity $\left(\mathrm{I}_{\mathrm{Na}}\right)$ is significantly decreased. These animals experience a reduction in heart rate, impaired atrioventricular conduction, increased PR intervals, and increased QRS intervals [14]. Further, AnkG cKO mice display arrhythmias in response to adrenergic stimulation. In humans, an SCN5A variant in the AnkG-binding motif of $\mathrm{Na}_{\mathrm{V}} 1.5$ has been associated with Brugada syndrome and arrhythmia [12]. This same variant is a loss-of-function variant when expressed in primary cardiomyocytes. Similar to other ankyrin genes, ANK3 encodes multiple isoforms of AnkG. Giant AnkG is a 480-kD protein required for proper AIS and node of Ranvier assembly due to the clustering of $\mathrm{Na}_{\mathrm{V}}$ channels [35]. Human variants affecting $480-\mathrm{kD}$ AnkG are associated with severe cognitive disability [29]. The role of Giant AnkG isoforms in the heart is currently unknown and is an important area for future research.

AnkB and AnkG are ubiquitously expressed, but their functions are distinct. Although AnkG plays a crucial role in the brain, variants in AnkG have been connected to Brugada syndrome [12] and, more recently, dilated cardiomyopathy [28]. Although AnkB and AnkG have similar structures, AnkG partners with proteins at the intercalated disc, including plakophilin-2 [23] and $\mathrm{Na}_{\mathrm{V}} 1.5$ [14], while AnkB is crucial for the expression and localization of ion channels at the sarcoplasmic reticulum, transverse-tubules, and plasma membrane [12]. However, Roberts et al. recently identified small 
populations of AnkB at the intercalated disc [27]. Cardiomyocytes from mice heterozygous for a null mutation in ankyrin-B display mislocalization and a decrease in expression of $\mathrm{Na}^{+} / \mathrm{Ca}^{2+}$ exchanger (NCX) and $\mathrm{Na}^{+} / \mathrm{K}^{+}$-ATPase (NKA) [36]. Further, Roberts et al. demonstrated that $\beta$-catenin is a novel AnkB-binding partner, where $\beta$-catenin localization is disrupted in individuals with ANK2 variants who presented with arrhythmogenic right ventricular cardiomyopathy (ARVC) [27]. Importantly, ankyrins - $G$ and -B retain non-overlapping, non-compensatory functions despite their similarity in sequence. Distinct from AnkG-associated disease, variants in AnkB are tied to a specific set of clinical phenotypes, including susceptibilities to sinus node dysfunction and acquired heart diseases such as atrial fibrillation [12] and heart failure [37]. Ankyrin specificity, at least in part, is attributed to an autoinhibitory linker peptide between the membrane-binding domain (MBD) and spectrin-binding domain (SBD), which prevents AnkB from binding with protein partners [38]. Further specificity is attributed to key roles of the divergent $C$-terminal domains of AnkB and AnkG. Additional mechanisms underlying ankyrin specificity in vivo are a key area for future research.

\section{Ankyrin-B Isoforms}

Similar to ANK1 and ANK3, ANK2 generates multiple gene products. The diversity of known and potential gene products is large and includes splice products defined as small, canonical, and Giant AnkB isoforms [13]. In fact, The National Center for Biotechnology Information gene database (NCBI Gene) lists 49 transcript variants that match the known RefSeq (NM) and 20 transcript variants that match the model RefSeq $(\mathrm{XM})$, yet most of these transcript variants have not been identified in tissue or cells.

AnkB-188 and AnkB-212 are two ankyrin-B isoforms present in the heart [24]. AnkB-188 is expressed in human ventricular cardiomyocytes and regulates NCX expression, whereas AnkB-212 is expressed in cardiomyocytes and skeletal muscle, is localized to the M-line, and exclusively interacts with obscurin [24]. Furthermore, 440kD AnkB (Giant AnkB) is the result of the insertion of a $6.4 \mathrm{~kb}$ exon between the SBD and death domain (DD). To date, expression of Giant AnkB has only been studied in neurons and was recently associated with autism [25]. Giant AnkB regulates the expression and localization of L1CAMs in neurons and predominates in unmyelinated axons to control axonal branching. A mouse model deficient in Giant AnkB shows increased axonal branching and a transient increase in excitatory synapses during postnatal development [39]. Although there are a host of ankyrin-B isoforms in the heart, the primary isoform is canonical 220-kD AnkB.

Canonical AnkB is an adaptor protein that acts as a pivotal regulator in the localization and organization of ion channels, structural proteins, signaling molecules, and adaptor proteins $[40,41]$. Deficiency in AnkB results in mislocalization and altered expression of multiple membrane and cytoskeletal proteins, including NCX [12], NKA [18], ATP-sensitive inward rectifier $\mathrm{K}^{+}$channel

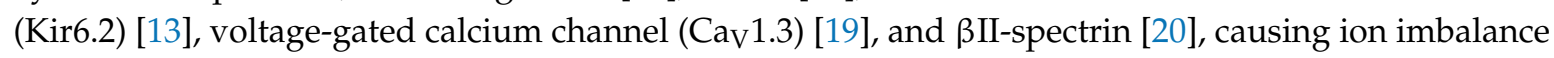
and dysregulation of cellular signaling [18].

Animal models have been fundamental in illustrating the role of AnkB in the heart. AnkB ${ }^{+/-}$ myocytes display reduced expression and improper localization of AnkB-binding partners, as well as strong electrical phenotypes including extrasystoles, early afterdepolarizations (EADs), and delayed afterdepolarizations (DADs) following adrenergic stimulation. The mechanism underlying AnkB-associated arrhythmias is attributed to improper calcium handling via disrupted organization of AnkB-binding partners [36]. Through the use of a canine cardiomyocyte model, Chu et al. predicted that mislocalization of the NKA and its subsequent uncoupling from the NCX in AnkB ${ }^{+/}$cardiomyocytes disturbs $\mathrm{Ca}^{2+}$ and $\mathrm{Na}^{+}$currents to predispose the cell to action potential prolongation [42].

\section{Ankyrin-B Structure and Binding Partners}

Canonical ankyrin proteins share a similar structure composed of an MBD, SBD, and a regulatory domain (RD) that is comprised of a death domain (DD) and C-terminal domain (CTD) (Figure 1). The MBD of AnkB is divided into four subdomains composed of 24 ANK repeats, which are defined by 
their repeated alpha-helical structure [43]. ANK repeats are not specific to the three canonical ankyrin proteins and are present across a range of functionally diverse proteins including SHANK, BARD1, and ANKRD. The AnkB MBD regulates the localization of ion channels and transporters (Figure 2 and Table 2).

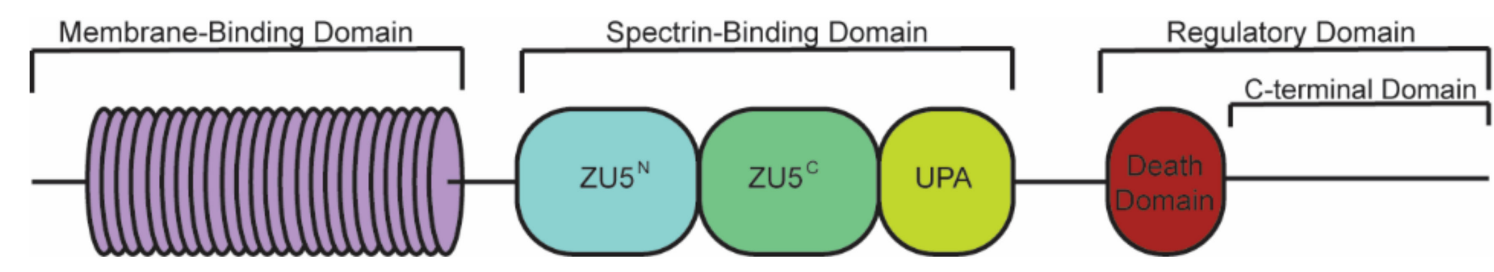

Figure 1. Structure of canonical ankyrin-B. Canonical ankyrin proteins share four domains: a membrane-binding domain (MBD), spectrin-binding domain (SBD), death domain (DD), and C-terminal domain (CTD). The MBD consists of $24 A N K$ repeats that are defined by their secondary structure and aid in protein folding regulation. The SBD consists of ZU5N, ZU5C, and UPA domains that are important for binding $\beta$ II-spectrin and supporting cardiomyocyte structure. The DD and CTD comprise the regulatory domain.

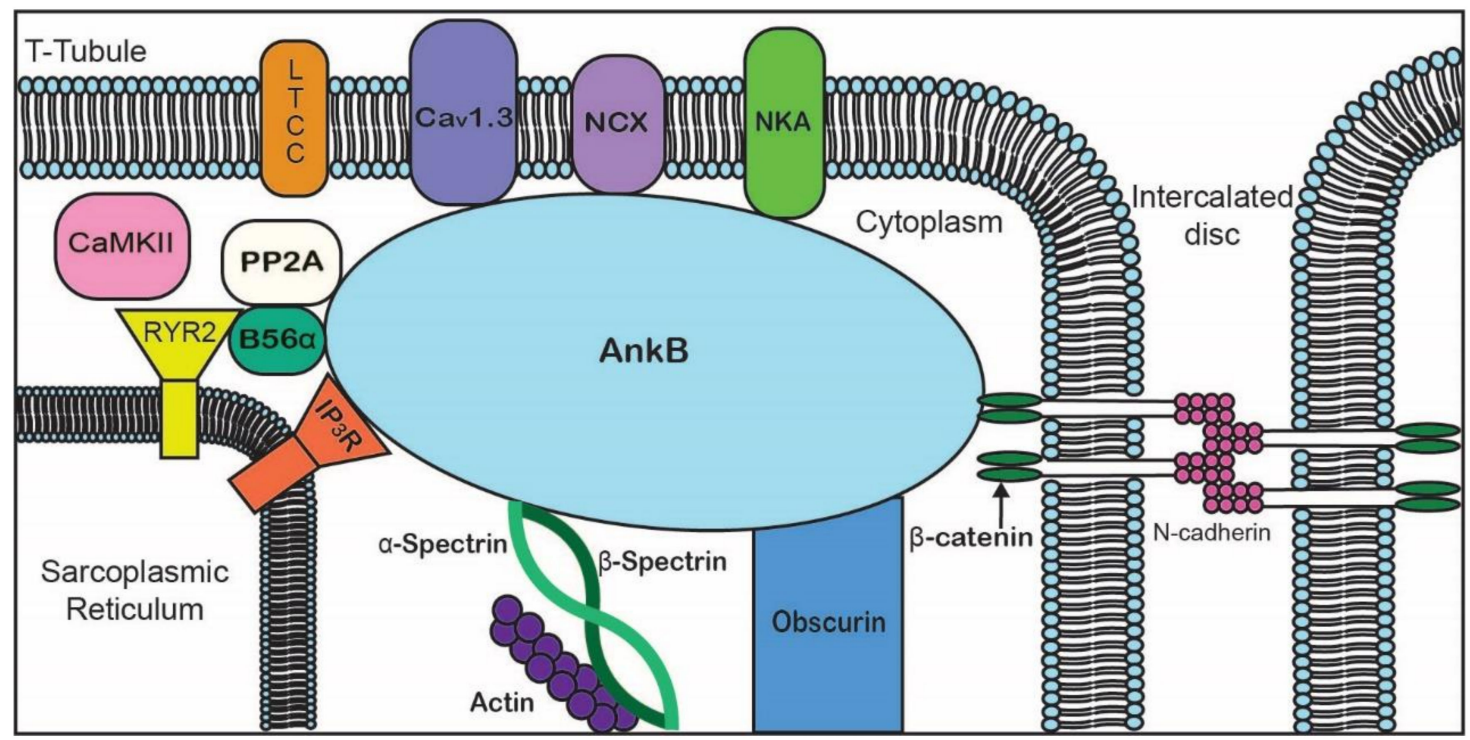

Figure 2. Representative diagram of ankyrin-B-binding partners to emphasize the importance of AnkB in the localization of ion channels, transporters, pumps, and structural proteins for proper cardiomyocyte function.

Table 2. Ankyrin-B-binding partners in the heart.

\begin{tabular}{|c|c|c|c|}
\hline \multicolumn{2}{|c|}{ Membrane-Binding Domain } & \multirow{2}{*}{$\frac{\text { Spectrin-Binding Domain }}{\beta \text {-spectrin }}$} & \multirow{2}{*}{$\frac{\text { Regulatory Domain }}{\text { HSP } 40}$} \\
\hline Ion channels & Transporters/Pumps & & \\
\hline$\overline{I P 3 R}$ & $\overline{\text { Anion Exchanger }}$ & $\mathrm{PP} 2 \mathrm{~A}$ & Obscurin \\
\hline $\mathrm{Ca}_{\mathrm{v}} 1.3$ & $\mathrm{Na} / \mathrm{Ca}$ Exchanger & & Ankyrin MBD \\
\hline Kir6.2 & $\mathrm{Na} / \mathrm{K}$ ATPase & & \\
\hline Structural & Cell adhesion & & \\
\hline Tubulin $\beta$-catenin & $\overline{\text { L1CAMs }}$ & & \\
\hline & $\beta$-dystroglycan & & \\
\hline & Dystrophin & & \\
\hline
\end{tabular}

IP3R $=1,4,5$ inositol trisphosphate receptor, $\mathrm{Ca}_{\mathrm{V}} 1.3=$ voltage-gated $\mathrm{Ca}^{2+}$ channel, Kir6. 2 = ATP-sensitive inward rectifier $\mathrm{K}^{+}$channel, $\mathrm{PP} 2 \mathrm{~A}=$ protein phosphatase $2 \mathrm{~A}, \mathrm{HSP} 40=$ heat shock protein $40, \mathrm{MBD}=$ membrane binding domain, L1CAMs = L1 family of neural cell adhesion molecules.

The SBD is a highly conserved region of most ankyrin proteins, where the AnkB SBD is composed of a ZU5 ${ }^{\mathrm{N}}-$ ZU5 ${ }^{\mathrm{C}}$-UPA tandem structure. The ZU5 ${ }^{\mathrm{N}}$ domain binds directly with the spectrin cytoskeleton 
to aid in the structural integrity of the myocyte [44]. Critical to calcium handling in the heart, the ankyrin $\mathrm{ZU}^{\mathrm{C}}$ region of the AnkB-SBD associates with the B56 $\alpha$ subunit of protein phosphatase $2 \mathrm{~A}$ (PP2A), an interaction that localizes PP2A with a primary target, RyR2 [12,13]. The ANK2 p.Q1283H variant within ZU5c was recently associated with arrhythmia, potentially due to loss of PP2A activity and altered phosphorylation of RyR2 [45].

The AnkB DD, composed of six helices that resemble the death domain of apoptotic-related proteins, is proposed to play a role in the auto-inhibitory functions of AnkB through the binding of the DD to the UPA region of SBD [44]. Additionally, a yeast two-hybrid screen and subsequent co-immunoprecipitation revealed that the AnkB DD binds RAB GTPase activating protein-1 like (RABGAP1L), which is involved in intracellular membrane trafficking within many different cell types, including heart tissue [46]. Although the regulatory domain is the least conserved domain of AnkB, the majority of disease-associated variants have been identified in this region. The DD variant, V1516D, was identified in four individuals with various heart conditions such as atrial fibrillation, drug-induced long QT syndrome (LQTS), exercise-induced ventricular tachycardia, bradycardia, syncope, or a combination of phenotypes [12].

Finally, the AnkB CTD is characterized by its elongated structure and its high composition of charged amino acids [12]. It is highly divergent and interacts with obscurin [47]. The CTD structure allows for inter-domain interactions that are crucial to isoform-specific functions. Intramolecular interactions between the AnkB CTD and MBD are proposed to regulate protein binding interactions. Ankyrin auto-regulatory activity was originally identified in AnkR and its splice variant AnkR 2.2 [48,49]. Within AnkB, yeast two-hybrid studies identified essential amino acid sequences of the CTD and MBD that are required for binding; Arg 37 and Arg 40 of the ANK repeat 1 within the MBD and the three amino acid sequence EED within the CTD are shown to facilitate inter-domain binding [12]. Abolishment of this interaction inhibits AnkB-specific targeting of inositol trisphosphate receptor (IP3R) to the sarcoplasmic reticulum, therefore demonstrating that inter-domain interactions are responsible for ankyrin function through regulation of proper protein interactions. Interestingly, however, these amino acid sequences are not required for binding of AnkB MBD with the IP3R, raising questions about the role of the CTD in localization and expression of AnkB-binding partners within the heart.

\section{Ankyrin-B Variants in Cardiovascular Disease}

AnkB variants have been identified in all four domains of the AnkB protein and are linked to a spectrum of cardiovascular phenotypes. AnkB is classically associated with human arrhythmia syndromes, many of which demonstrate incomplete penetrance and variable expressivity [12,50-52]. In fact, it is likely that secondary genetic, lifestyle, and/or environmental factors are necessary to cause disease. Ankyrin-B syndrome, originally classified as long QT syndrome type 4, is a heritable arrhythmogenic disease that is the result of loss-of-function mutations in ANK2. A p.E1425G variant was discovered in a French family suffering from sinus bradycardia, atrial fibrillation, and sudden cardiac death and was the first to be implicated in AnkB syndrome [12,53].

Although the p.E1425G variant is localized to the AnkB regulatory domain, loss-of-function variants in all four ankyrin domains are now associated with AnkB syndrome [12,54]. Notably, these variants show a range of clinical severity and phenotypes, including torsades de pointes (TdP), ventricular tachycardia, and long QT syndrome, a variability that is reflected at the cellular level [12]. This inconsistency of phenotype puts into the question the mechanics behind AnkB-associated diseases that have yet to be fully elucidated. Although the AnkB MBD is imperative for AnkB interactions and function within the heart, the first disease-associated loss-of-function variant in this domain, p.S646F, was only recently identified within the First Nations of Northern British Columbia [54]. Individuals with this variant also exhibited congenital heart defects, Wolff-Parkinson-White syndrome, and cardiomyopathy. These compounded symptoms are the result of improper NCX localization, subsequent $\mathrm{Ca}^{2+}$ overload, and possible disruption of pacemaking activity $[12,36]$. 
Variants within the SBD pose distinct mechanisms of disease. Several AnkB variants including the p.R990Q [20], p.A1000P, and p.DAR976AAA are present within the highly conserved ZU5 ${ }^{\mathrm{N}}$ region of the SBD that directly binds $\beta$ III-spectrin, disrupting this interaction. Importantly, AnkB co-immunoprecipitates with a larger complex composed of $\beta$ II-spectrin, NKA, and NCX [20]. Although p.A1000P and p.DAR976AAA demonstrated normal AnkB activity with altered $\beta$ II-spectrin binding, the p.R990Q variant showed altered AnkB functionality, including an inability to rescue NCX localization in AnkB knockout myocytes and severe arrhythmia attributed to disruption of the AnkB-spectrin interaction [20]. Notably, the p.Q1283H variant within the $\mathrm{ZU}^{\mathrm{C}}$ region disrupts PP2A activity via loss of B56 $\alpha$ targeting, which increases RyR2 phosphorylation and disrupts the calcium dynamics associated with excitation-contraction (EC) coupling [45]. Notably, alterations in RyR2 activity are associated with dilated cardiomyopathy and offer an additional area for future investigation.

Variants in ANK2 have also been associated with sinus node disease (SND) [12] and most recently with arrhythmogenic cardiomyopathy (ACM) [27]. In fact, the p.E1425G variant segregated with sinus node disease with nearly complete penetrance [45]. Similar to ANK2 loss of function mutations, ANK2 transection in chromosome 4, leading to ANK2 haploinsufficiency, was associated with ankyrin-B syndrome [55].

Although AnkB is commonly associated with arrhythmias, variants in ANK2 have also been associated with structural heart disease. Lopes et al. found that individuals with ANK2 variants had a greater maximum wall thickness in the left ventricle, in hypertrophic cardiomyopathy [50]. AnkB has also been linked to acquired heart disease and tissue remodeling following infarct in canine animal models [12]. Following coronary artery occlusion, AnkB mRNA and protein levels decrease in the cardiomyocytes found at the infarct border zone (BZ), as do common AnkB-binding partners including NCX and NKA. These findings provide new insight into the role of AnkB in heart failure and possibly for the cardiac remodeling that supports the creation of arrhythmogenic substrates at the border zone [37].

Recently, ANK2 variants have been identified in individuals with arrhythmogenic right ventricular cardiomyopathy (ARVC) [27], a disease characterized by a severe structural and electrical cardiac phenotype that involves the fibrofatty replacement of healthy myocardium, malignant arrhythmias, and even sudden cardiac death [56]. The AnkB-p.Glu1458Gly variant was linked to AnkB syndrome but was also identified in a family with AnkB syndrome found to have ARVC at autopsy [27]. A larger screen that encompassed AnkB variants in ACM revealed a loss-of-function variant, AnkB-p.Met1988Thr, which segregated with ARVC-affected family members, where staining of the ventricle tissue showed reduced levels of NCX at the plasma membrane and abnormal Z-line targeting [27]. In order to model the ACM phenotype seen in these patients with loss-of-function AnkB variants and ACM, a cardiomyocyte-specific AnkB knockout mouse was generated (as AnkB null mice die shortly after birth), which developed a phenotype similar to that of human ACM, including dramatic structural abnormalities, biventricular dilation, reduced ejection fraction, cardiac fibrosis, premature death, and exercise-induced death [27]. Although the desmosome was preserved in these mice, $\beta$-catenin localization was altered, and $\beta$-catenin was demonstrated as a binding partner for the AnkB MBD. Interestingly, when these mice were treated with GSK-3 $\beta$-inhibitor, a pharmacological activator of $\beta$-catenin, it prevented and partially reversed the ARVC phenotype found in these mice [27], providing a hopeful outlook on developing new therapies for patients with AnkB variant-driven ARVC.

\section{Future Implications}

ANK2 variants are associated with cardiovascular phenotypes including sinus node disease, atrial fibrillation, heart rate variability, catecholaminergic polymorphic ventricular tachycardia (CPVT), ACM, cardiomyopathy, syncope, and sudden cardiac death. We strongly predict that disease penetrance and severity will ultimately be predicated by the interaction between genetic (known as well as currently unknown variants, deletions, etc.) and environmental factors. A key future area of research is to 
understand the impact of secondary variants and acquired/environmental factors (e.g., ischemia, catecholamines) on ankyrin-B stability and disease.

Despite their variability, the majority of treatment options for AnkB-associated conditions continue to mitigate the clinical symptoms of disease as opposed to their molecular causes. Currently, SND, ARVC, and AnkB syndrome necessitate symptom-dependent approaches ranging from $\beta$-blocker administration to pacemaker implantation $[12,37,56]$. Only recently was SB-216763, a GSK-3 $\beta$ inhibitor, identified to both prevent and reverse ARVC in mice by targeting a specific interaction between AnkB and $\beta$-catenin through the Wnt signaling pathway [27], but this therapeutic strategy has not yet been tested. Although the authors posit that the drug may function by altering $\beta$-catenin phosphorylation levels, the exact mechanics of its action remain unclear, which highlights the need for future examination. Furthermore, these findings address the structural phenotype of ARVC that is largely absent in SND and AnkB syndrome, again establishing the need for more disease-specific therapeutic options.

The clinical manifestations of AnkB-attributed pathologies are also intriguingly patient specific. For example, cases of ARVC and AnkB syndrome, which comprise disparate structural and electrical phenotypes, have both been linked to the AnkB E1425G variant [27]. This genetic overlap demonstrates that individual AnkB variants are not likely the sole determinants of a given clinical phenotype, but rather are compounded by environmental factors that work in conjunction with additional genetic factors to produce disease variability. Further study is necessary to elucidate the synergistic interactions and intricate molecular pathways that could act as novel therapeutic targets in AnkB-associated illness.

In summary, AnkB is critical for the expression, targeting, and regulation of multiple proteins involved in cardiac excitability, structure, and signaling. AnkB is a pivotal regulator of ion channels and transporters (e.g., NCX and NKA), structural proteins (e.g., $\beta$ II-spectrin and $\beta$-catenin), and calcium regulatory proteins (e.g., RyR2 and PP2A) (Figure 2). Together, the diverse roles of AnkB contribute to EC coupling, cytoskeletal integrity, and signaling pathways required for proper cardiomyocyte function. Variants in AnkB are associated with arrhythmogenic diseases that include both structural and electrical dysfunction. Although AnkB isoforms have been shown to have unique functions in the heart (AnkB-188 and AnkB-212), it is not known if variants in these isoforms contribute to disease. Since AnkB-188 plays a role in localization of NCX and AnkB-212 binds obscurin, variants may lead to M-line disruption in cardiomyocyte conduction and contraction, as knockdown of either isoform resulted in arrhythmic contraction in vitro [24]. Although Giant AnkB has only been studied in the brain, where variants may increase susceptibility to cognitive disorders and autism, its expression and role in heart disease has yet to be determined. Understanding the role of AnkB variants in disease, along with other variants that contribute to the phenotypes described here, is crucial to developing new treatment strategies for complex human disease.

Author Contributions: All authors listed have made substantial direct and intellectual contribution to the work, and approved it for publication.

Funding: This work was supported by NIH grants HL135754 and HL134824 to PJM, HL146969 to MER, and by a grant from the Ohio State Frick Center for Heart Failure and Arrhythmia, the Linda and Joe Chlapaty Center for Atrial Fibrillation, and JB Project.

Conflicts of Interest: The authors declare no conflict of interest.

\section{References}

1. Bennett, V.; Stenbuck, P.J. Identification and partial purification of ankyrin, the high affinity membrane attachment site for human erythrocyte spectrin. J. Biol. Chem. 1979, 254, 2533-2541. [PubMed]

2. Bennett, V.; Davis, J.; Fowler, W.E. Immunoreactive forms of erythrocyte spectrin and ankyrin in brain. Philos. Trans. R. Soc. Lond. Ser. Biol. Sci. 1982, 299, 301-312. [CrossRef] [PubMed]

3. Bennett, V.; Davis, J. Spectrin and ankyrin in brain. Cell Motil. 1983, 3, 623-633. [CrossRef] [PubMed]

4. Davis, J.Q.; Bennett, V. Brain ankyrin. Purification of a 72,000 Mr spectrin-binding domain. J. Biol. Chem. 1984, 259, 1874-1881. 
5. Moon, R.T.; Ngai, J.; Wold, B.J.; Lazarides, E. Tissue-specific expression of distinct spectrin and ankyrin transcripts in erythroid and nonerythroid cells. J. Cell Biol. 1985, 100, 152-160. [CrossRef]

6. Nelson, W.J.; Lazarides, E. Posttranslational control of membrane-skeleton (ankyrin and alpha beta-spectrin) assembly in early myogenesis. J. Cell Biol. 1985, 100, 1726-1735. [CrossRef]

7. Otto, E.; Kunimoto, M.; McLaughlin, T.; Bennett, V. Isolation and characterization of cDNAs encoding human brain ankyrins reveal a family of alternatively spliced genes. J. Cell Biol. 1991, 114, 241-253. [CrossRef]

8. Davis, J.Q.; Bennett, V. Brain ankyrin. A membrane-associated protein with binding sites for spectrin, tubulin, and the cytoplasmic domain of the erythrocyte anion channel. J. Biol. Chem. 1984, 259, 13550-13559.

9. Lambert, S.; Yu, H.; Prchal, J.T.; Lawler, J.; Ruff, P.; Speicher, D.; Cheung, M.C.; Kan, Y.W.; Palek, J. cDNA sequence for human erythrocyte ankyrin. Proc. Natl. Acad. Sci. USA 1990, 87, 1730-1734. [CrossRef]

10. Ho, T.S.-Y.; Zollinger, D.R.; Chang, K.-J.; Xu, M.; Cooper, E.C.; Stankewich, M.C.; Bennett, V.; Rasband, M.N. A hierarchy of ankyrin-spectrin complexes clusters sodium channels at nodes of Ranvier. Nat. Neurosci. 2014, 17, 1664-1672. [CrossRef] [PubMed]

11. Pierantozzi, E.; Szentesi, P.; Al-Gaadi, D.; Oláh, T.; Dienes, B.; Sztretye, M.; Rossi, D.; Sorrentino, V.; Csernoch, L. Calcium Homeostasis Is Modified in Skeletal Muscle Fibers of Small Ankyrin1 Knockout Mice. Int. J. Mol. Sci. 2019, 20, 3361. [CrossRef] [PubMed]

12. Curran, J.; Mohler, P.J. Coordinating electrical activity of the heart: Ankyrin polypeptides in human cardiac disease. Expert Opin. Targets 2011, 15, 789-801. [CrossRef]

13. Cunha, S.R.; Mohler, P.J. Ankyrin-based cellular pathways for cardiac ion channel and transporter targeting and regulation. Semin. Cell Dev. Biol. 2011, 22, 166-170. [CrossRef] [PubMed]

14. Makara, M.A.; Curran, J.; Little, S.C.; Musa, H.; Polina, I.; Smith, S.A.; Wright, P.J.; Unudurthi, S.D.; Snyder, J.; Bennett, V.; et al. Ankyrin-G coordinates intercalated disc signaling platform to regulate cardiac excitability in vivo. Circ. Res. 2014, 115, 929-938. [CrossRef]

15. Kalomiris, E.L.; Bourguignon, L.Y. Mouse T lymphoma cells contain a transmembrane glycoprotein (GP85) that binds ankyrin. J. Cell Biol. 1988, 106, 319-327. [CrossRef] [PubMed]

16. Nelson, W.J.; Veshnock, P.J. Ankyrin binding to $\left(\mathrm{Na}^{+}+\mathrm{K}^{+}\right)$ATPase and implications for the organization of membrane domains in polarized cells. Nature 1987, 328, 533-536. [CrossRef]

17. Nicolas, V.; Le Van Kim, C.; Gane, P.; Birkenmeier, C.; Cartron, J.-P.; Colin, Y.; Mouro-Chanteloup, I. Rh-RhAG/Ankyrin-R, a New Interaction Site between the Membrane Bilayer and the Red Cell Skeleton, Is Impaired by Rhnull-associated Mutation. J. Biol. Chem. 2003, 278, 25526-25533. [CrossRef]

18. Skogestad, J.; Aronsen, J.M.; Tovsrud, N.; Wanichawan, P.; Hougen, K.; Stokke, M.K.; Carlson, C.R.; Sjaastad, I.; Sejersted, O.M.; Swift, F. Coupling of the Na+/K+-ATPase to Ankyrin B controls Na+/Ca2+ exchanger activity in cardiomyocytes. Cardiovasc. Res. 2019. [CrossRef]

19. Wolf, R.M.; Glynn, P.; Hashemi, S.; Zarei, K.; Mitchell, C.C.; Anderson, M.E.; Mohler, P.J.; Hund, T.J. Atrial fibrillation and sinus node dysfunction in human ankyrin-B syndrome: A computational analysis. Am. J. Physiol. Heart Circ. Physiol. 2013, 304, H1253-H1266. [CrossRef]

20. Smith, S.A.; Sturm, A.C.; Curran, J.; Kline, C.F.; Little, S.C.; Bonilla, I.M.; Long, V.P.; Makara, M.; Polina, I.; Hughes, L.D.; et al. Dysfunction in the BII spectrin-dependent cytoskeleton underlies human arrhythmia. Circulation 2015, 131, 695-708. [CrossRef]

21. Kordeli, E.; Lambert, S.; Bennett, V. Ankyrin: A new ankyrin gene with neural-specific isoforms localized at the axonal initial segment and node of ranvier. J. Biol. Chem. 1995, 270, 2352-2359. [CrossRef] [PubMed]

22. Jenkins, S.M.; Bennett, V. Ankyrin-G coordinates assembly of the spectrin-based membrane skeleton, voltage-gated sodium channels, and L1 CAMs at Purkinje neuron initial segments. J. Cell Biol. 2001, 155, 739-746. [CrossRef] [PubMed]

23. Sato, P.Y.; Coombs, W.; Lin, X.; Nekrasova, O.; Green, K.J.; Isom, L.L.; Taffet, S.M.; Delmar, M. Interactions between ankyrin-G, Plakophilin-2, and Connexin43 at the cardiac intercalated disc. Circ. Res. 2011, 109, 193-201. [CrossRef] [PubMed]

24. Wu, H.C.; Yamankurt, G.; Luo, J.; Subramaniam, J.; Hashmi, S.S.; Hu, H.; Cunha, S.R. Identification and characterization of two ankyrin-B isoforms in mammalian heart. Cardiovasc. Res. 2015, 107, 466-477. [CrossRef] [PubMed]

25. Kunimoto, M.; Otto, E.; Bennett, V. A new 440-kD isoform is the major ankyrin in neonatal rat brain. J. Cell Biol. 1991, 115, 1319-1331. [CrossRef] 
26. Perrotta, S.; Gallagher, P.G.; Mohandas, N. Hereditary spherocytosis. Lancet (Lond. Engl.) 2008, 372, 1411-1426. [CrossRef]

27. Roberts, J.D.; Murphy, N.P.; Hamilton, R.M.; Lubbers, E.R.; James, C.A.; Kline, C.F.; Gollob, M.H.; Krahn, A.D.; Sturm, A.C.; Musa, H.; et al. Ankyrin-B dysfunction predisposes to arrhythmogenic cardiomyopathy and is amenable to therapy. J. Clin. Investig. 2019, 129, 3171-3184. [CrossRef]

28. Makara, M.A.; Curran, J.; Lubbers, E.R.; Murphy, N.P.; Little, S.C.; Musa, H.; Smith, S.A.; Unudurthi, S.D.; Rajaram, M.V.S.; Janssen, P.M.L.; et al. Novel Mechanistic Roles for Ankyrin-G in Cardiac Remodeling and Heart Failure. Jacc Basic Transl. Sci. 2018, 3, 675-689. [CrossRef]

29. Iqbal, Z.; Vandeweyer, G.; van der Voet, M.; Waryah, A.M.; Zahoor, M.Y.; Besseling, J.A.; Roca, L.T.; Vulto-van Silfhout, A.T.; Nijhof, B.; Kramer, J.M.; et al. Homozygous and heterozygous disruptions of ANK3: At the crossroads of neurodevelopmental and psychiatric disorders. Hum. Mol. Genet. 2013, 22, 1960-1970. [CrossRef]

30. Bennett, V.; Stenbuck, P.J. The membrane attachment protein for spectrin is associated with band 3 in human erythrocyte membranes. Nature 1979, 280, 468-473. [CrossRef]

31. Narla, J.; Mohandas, N. Red cell membrane disorders. Int. J. Lab. Hematol. 2017, 39, 47-52. [CrossRef] [PubMed]

32. Satchwell, T.J.; Bell, A.J.; Hawley, B.R.; Pellegrin, S.; Mordue, K.E.; van Deursen, C.T.B.M.; Braak, N.H.-T.; Huls, G.; Leers, M.P.G.; Overwater, E.; et al. Severe Ankyrin-R deficiency results in impaired surface retention and lysosomal degradation of RhAG in human erythroblasts. Haematologica 2016, 101, 1018-1027. [CrossRef] [PubMed]

33. Bennett, V.; Baines, A.J. Spectrin and ankyrin-based pathways: Metazoan inventions for integrating cells into tissues. Physiol. Rev. 2001, 81, 1353-1392. [CrossRef] [PubMed]

34. Curran, J.; Mohler, P.J. Alternative paradigms for ion channelopathies: Disorders of ion channel membrane trafficking and posttranslational modification. Annu. Rev. Physiol. 2015, 77, 505-524. [CrossRef] [PubMed]

35. Jenkins, P.M.; Kim, N.; Jones, S.L.; Tseng, W.C.; Svitkina, T.M.; Yin, H.H.; Bennett, V. Giant ankyrin-G: A critical innovation in vertebrate evolution of fast and integrated neuronal signaling. Proc. Natl. Acad. Sci. USA 2015, 112, 957-964. [CrossRef] [PubMed]

36. Camors, E.; Mohler, P.J.; Bers, D.M.; Despa, S. Ankyrin-B reduction enhances Ca spark-mediated SR Ca release promoting cardiac myocyte arrhythmic activity. J. Mol. Cell Cardiol. 2012, 52, 1240-1248. [CrossRef] [PubMed]

37. Kashef, F.; Li, J.; Wright, P.; Snyder, J.; Suliman, F.; Kilic, A.; Higgins, R.S.D.; Anderson, M.E.; Binkley, P.F.; Hund, T.J.; et al. Ankyrin-B protein in heart failure: Identification of a new component of metazoan cardioprotection. J. Biol. Chem. 2012, 287, 30268-30281. [CrossRef]

38. He, M.; Tseng, W.-C.; Bennett, V. A single divergent exon inhibits ankyrin-B association with the plasma membrane. J. Biol. Chem. 2013, 288, 14769-14779. [CrossRef]

39. Yang, R.; Walder-Christensen, K.K.; Kim, N.; Wu, D.; Lorenzo, D.N.; Badea, A.; Jiang, Y.-H.; Yin, H.H.; Wetsel, W.C.; Bennett, V. ANK2 autism mutation targeting giant ankyrin-B promotes axon branching and ectopic connectivity. Proc. Natl. Acad. Sci. USA 2019, 116, 15262-15271. [CrossRef]

40. Koenig, S.N.; Mohler, P.J. The evolving role of ankyrin-B in cardiovascular disease. Heart Rhythm 2017, 14, 1884-1889. [CrossRef]

41. El Refaey, M.M.; Mohler, P.J. Ankyrins and Spectrins in Cardiovascular Biology and Disease. Front. Physiol. 2017, 8, 852. [CrossRef] [PubMed]

42. Chu, L.; Greenstein, J.L.; Winslow, R.L. $\mathrm{Na}^{+}$microdomains and sparks: Role in cardiac excitation-contraction coupling and arrhythmias in ankyrin-B deficiency. J. Mol. Cell Cardiol. 2019, 128, 145-157. [CrossRef] [PubMed]

43. Michaely, P.; Tomchick, D.R.; Machius, M.; Anderson, R.G.W. Crystal structure of a 12 ANK repeat stack from human ankyrinR. Embo. J. 2002, 21, 6387-6396. [CrossRef] [PubMed]

44. Wang, C.; Yu, C.; Ye, F.; Wei, Z.; Zhang, M. Structure of the ZU5-ZU5-UPA-DD tandem of ankyrin-B reveals interaction surfaces necessary for ankyrin function. Proc. Natl. Acad. Sci. USA 2012, 109, 4822-4827. [CrossRef]

45. Zhu, W.; Wang, C.; Hu, J.; Wan, R.; Yu, J.; Xie, J.; Ma, J.; Guo, L.; Ge, J.; Qiu, Y.; et al. Ankyrin-B Q1283H Variant Linked to Arrhythmias Via Loss of Local Protein Phosphatase 2A Activity Causes Ryanodine Receptor Hyperphosphorylation. Circulation 2018, 138, 2682-2697. [CrossRef] 
46. Qu, F.; Lorenzo, D.N.; King, S.J.; Brooks, R.; Bear, J.E.; Bennett, V. Ankyrin-B is a PI3P effector that promotes polarized $\alpha 5 \beta 1$-integrin recycling via recruiting RabGAP1L to early endosomes. Elife 2016, 5, e20417. [CrossRef]

47. Kontrogianni-Konstantopoulos, A.; Bloch, R.J. Obscurin: A multitasking muscle giant. J. Muscle Res. Cell Motil. 2005, 26, 419-426. [CrossRef]

48. Hall, T.G.; Bennett, V. Regulatory domains of erythrocyte ankyrin. J. Biol. Chem. 1987, 262, 10537-10545.

49. Davis, L.H.; Davis, J.Q.; Bennett, V. Ankyrin regulation: An alternatively spliced segment of the regulatory domain functions as an intramolecular modulator. J. Biol. Chem. 1992, 267, 18966-18972.

50. Lopes, L.R.; Syrris, P.; Guttmann, O.P.; O’Mahony, C.; Tang, H.C.; Dalageorgou, C.; Jenkins, S.; Hubank, M.; Monserrat, L.; McKenna, W.J.; et al. Novel genotype-phenotype associations demonstrated by high-throughput sequencing in patients with hypertrophic cardiomyopathy. Heart 2015, 101, $294-301$. [CrossRef]

51. Ichikawa, M.; Aiba, T.; Ohno, S.; Shigemizu, D.; Ozawa, J.; Sonoda, K.; Fukuyama, M.; Itoh, H.; Miyamoto, Y.; Tsunoda, T.; et al. Phenotypic Variability of ANK2 Mutations in Patients With Inherited Primary Arrhythmia Syndromes. Circ. J. 2016, 80, 2435-2442. [CrossRef] [PubMed]

52. Robaei, D.; Ford, T.; Ooi, S.-Y. Ankyrin-B Syndrome: A Case of Sinus Node Dysfunction, Atrial Fibrillation and Prolonged QT in a Young Adult. Heartlung Circ. 2015, 24, e31-e34. [CrossRef] [PubMed]

53. Schott, J.J.; Charpentier, F.; Peltier, S.; Foley, P.; Drouin, E.; Bouhour, J.B.; Donnelly, P.; Vergnaud, G.; Bachner, L.; Moisan, J.P. Mapping of a gene for long QT syndrome to chromosome 4q25-27. Am. J. Hum. Genet. 1995, 57, 1114-1122. [PubMed]

54. Swayne, L.A.; Murphy, N.P.; Asuri, S.; Chen, L.; Xu, X.; McIntosh, S.; Wang, C.; Lancione, P.J.; Roberts, J.D.; Kerr, C.; et al. Novel Variant in the ANK2 Membrane-Binding Domain Is Associated With Ankyrin-B Syndrome and Structural Heart Disease in a First Nations Population With a High Rate of Long QT Syndrome. Circ. Cardiovasc. Genet. 2017, 10, e001537. [CrossRef]

55. Huq, A.J.; Pertile, M.D.; Davis, A.M.; Landon, H.; James, P.A.; Kline, C.F.; Vohra, J.; Mohler, P.J.; Delatycki, M.B. A Novel Mechanism for Human Cardiac Ankyrin-B Syndrome due to Reciprocal Chromosomal Translocation. Heart Lung Circ. 2017, 26, 612-618. [CrossRef] [PubMed]

56. Corrado, D.; Link, M.S.; Calkins, H. Arrhythmogenic Right Ventricular Cardiomyopathy. N. Engl. J. Med. 2017, 376, 61-72. [CrossRef] 